Revista Brasileira de Odontologia Legal - RBOL

\title{
Odontologia Legal
}

\section{REGISTRO DE INFORMAC̄̃̃ES ODONTOLÓGICAS PÓS MORTE COM FINS DE IDENTIFICAÇÃO HUMANA: DESCRIÇÃO DO PROTOCOLO UTILIZADO NO LAF-CEMEL.}

\section{Post mortem dental information for human identification: description of the protocol used in LAF-CEMEL.}

\author{
Karinna Fróes LIMA ${ }^{1}$, Beatriz Marques de Jesus FIGUEIREDO² ${ }^{2}$ Marco Aurélio \\ GUIMARÃES ${ }^{3}$, Ricardo Henrique Alves da SILVA ${ }^{4}$.
}

1. Universidade de São Paulo, Faculdade de Odontologia de Ribeirão Preto, Curso de Especialização em Odontologia Legal. Especialista em Odontologia Legal.

2. Universidade Estadual de Campinas, Faculdade de Odontologia de Piracicaba, Programa de Pós-Graduação em Biologia Buco-Dental. Aluno de Mestrado (Odontologia Legal).

3. Universidade de São Paulo, Faculdade de Medicina de Ribeirão Preto. Professor Associado (Medicina Legal).

4. Universidade de São Paulo, Faculdade de Odontologia de Ribeirão Preto. Professor Doutor (Odontologia Legal).

Informação sobre o manuscrito

Recebido em: 14 Fev 2017

Aceito em: 30 Maio 2017

\author{
Autor para contato: \\ Prof. Dr. Ricardo Henrique Alves da Silva \\ Universidade de São Paulo - Faculdade de Odontologia \\ de Ribeirão Preto. \\ Avenida do Café, s/n, Bairro Monte Alegre, Ribeirão \\ Preto, SP. CEP: 14040-904. \\ E-mail: ricardohenrique@usp.br.
}

\begin{abstract}
RESUMO
O protocolo do Laboratório de Antropologia Forense (LAF) do Centro de Medicina Legal (CEMEL) da Universidade de São Paulo (USP) foi estruturado para a obtenção de um perfil bioantropológico de cada ossada admitida para exame pericial, no intuito de apurar as características de sexo, ancestralidade, idade e estatura, além da análise de destreza manual. Com a inserção da análise odontológica na rotina do laboratório, foi organizado um protocolo odontolegal pela Faculdade de Odontologia de Ribeirão Preto (FORP) da USP, com a finalidade de sistematização e organização dos dados odontológicos coletados no exame post mortem para subsidiar processos que sejam passiveis de identificação por meio dos arcos dentais. O objetivo desse artigo é apresentar uma descrição do referido protocolo odontolegal. Conclui-se que o referido protocolo permite a coleta de uma série de informações odontológicas que podem ser utilizadas para fins de identificação humana.
\end{abstract}

\section{PALAVRAS-CHAVE}

Odontologia legal; Identificação humana; Antropologia forense.

\section{INTRODUÇÃO}

A Odontologia Legal é a especialidade odontológica que está relacionada ao Direito, por meio do fornecimento de esclarecimentos ou auxílio em questões judiciais, utilizando conhecimentos da área da Odontologia ${ }^{1} \mathrm{e}$, nesse sentido, a perícia odontolegal pode ser realizada em diversos âmbitos como civil, criminal, trabalhista e em sede administrativa ${ }^{2}$. 
No âmbito criminal, as questões que envolvam a área odontológica são realizadas por cirurgiões-dentistas investidos nos cargos de Perito Odontolegista ou de Perito Criminal, que estejam vinculados aos órgãos de perícias oficiais (Institutos de Medicina Legal - IML e Institutos de Criminalística - IC $)^{1}$. Especificamente em IMLs, o Perito Odontolegista, pelo seu conhecimento técnico-científico especializado, realiza diversos tipos de procedimentos, segundo atribuições estabelecidas pelo Conselho Federal de Odontologia (CFO), sendo as mais frequentes relacionadas a lesões traumáticas que atingem o complexo maxilomandibular, por agressões e acidentes de trânsito, e a identificação de cadáveres esqueletizados, putrefeitos ou carbonizados $^{1,3,4}$.

No município de Ribeirão Preto, estado de São Paulo, Brasil, por meio de um acordo de cooperação cientifica entre a Faculdade de Medicina de Ribeirão Preto da Universidade de São Paulo (FMRP-USP) e a University of Sheffield (Reino Unido), denominado "UK - Brazil Scientific Cooperation - Forensic Anthropology and Identification of Human Remains", financiado pelo Global Opportunities Fund do governo britânico, foi criado, em 2005, o Laboratório de Antropologia Forense (LAF), no Centro de Medicina Legal (CEMEL) da FMRP-USP e, a partir desta cooperação, foi elaborado um protocolo de trabalho com ossadas humanas que atendesse às exigências internacionais e que se adequasse à realidade local, dando respostas de modo rápido e confiável às necessidades de um exame antropológico forense, sendo este protocolo denominado LAF/CEMEL ${ }^{5}$.

O protocolo LAF/CEMEL consiste na obtenção de um perfil bioantropológico de cada caso, incluindo as seguintes características: determinação do sexo através da pelve e crânio; estimativa da ancestralidade pelo crânio e outros elementos; estimativa da idade em adultos (clavícula, sínfise púbica, articulação sacroilíaca, quarta costela e coluna vertebral); estimativa de idade em jovens (fechamento de cartilagens epifisárias dos ossos); estimativa da estatura (medidas de ossos longos) e estimativa da destreza manual (através da clavícula, úmero e rádio) ${ }^{5}$. No entanto, no momento da sua elaboração, a análise de características odontológicas era feita apenas por meio da indicação de dentes ausentes e presentes.

Com a parceria estabelecida entre 0 CEMEL-FMRP/USP e a área de Odontologia Legal da Faculdade de Odontologia de Ribeirão Preto da Universidade de São Paulo (FORP/USP), foi elaborado um protocolo odontolegal para sistematização e organização dos dados odontológicos coletados no exame post mortem para subsidiar processos que sejam passiveis de identificação por meio dos arcos dentais. Desta forma, o objetivo deste trabalho é apresentar a descrição do protocolo odontolegal utilizado no LAFCEMEL/FMRP-USP como meio de subsidiar outros serviços de Odontologia Legal para a implementação de um protocolo que possa ser utilizado na prática pericial, contribuindo com a missão do cirurgião-dentista em relação a sua atuação na identificação humana. 


\section{DESCRIÇÃO DO PROTOCOLO}

\section{Dados gerais}

A etapa inicial do Protocolo Odontolegal (LAF/CEMEL) consiste na descrição de informações gerais como: autoridade requisitante do exame, data do exame, local do exame e respectivos examinadores.

\section{Exame post mortem (PM)}

$$
\text { O exame necroscópico }
$$
propriamente dito, por inspeção direita, inicia-se com o detalhamento de todos os dentes presentes nos arcos dentais superior e inferior, sendo dividido em nomenclatura dental, notação dental (FDI) e comentários, que podem ser registrados na língua inglesa ou portuguesa, acerca das condições em que cada dente se encontra (Figuras 1 e 2 ).

Os arcos dentais são descritos no que diz respeito à ausência, presença, higidez, detalhamentos dos tratamentos observados (faces dentais, tipos de materiais, respectivamente), bem como a presença de características individualizadoras.

\begin{tabular}{|c|c|c|c|}
\hline Dente & Tooth & $\begin{array}{l}\text { Notação Dental } \\
\text { FDI World Dental } \\
\text { Federation Notation }\end{array}$ & Comentário / Comment \\
\hline Superior direm to & Her Rerir & 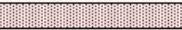 & (1) \\
\hline Incisivo central & Central incisor & 11 & \\
\hline Incisivo lateral & Lateral incisor & 12 & \\
\hline Canino & Canine & 13 & \\
\hline $1^{\circ}$ pré-molar & $1^{5 t}$ premolar & 14 & \\
\hline $2^{\circ}$ pré-molar & $2^{\text {nd }}$ premolar & 15 & \\
\hline $1^{\circ}$ molar & $1^{2}$ molar & 16 & \\
\hline $2^{\circ}$ molar & $2^{n s}$ molar & 17 & \\
\hline $3^{\circ}$ molar & $3^{\text {rt }}$ molar & 18 & \\
\hline esquerdo & Gpor Ler & & \\
\hline Incisivo central & Central incisor & 21 & \\
\hline Incisivo lateral & Lateral incisor & 22 & \\
\hline Canino & Canine & 23 & \\
\hline $1^{0}$ pré-molar & $1^{\text {st }}$ premolar & 24 & \\
\hline $2^{\circ}$ pré-molar & $2^{\text {not }}$ premolar & 25 & \\
\hline $1^{\circ}$ molar & $1^{2}$ molar & 26 & \\
\hline $2^{\circ}$ molar & $2^{105}$ molar & 27 & \\
\hline $3^{\circ} \mathrm{molar}$ & $3^{r s}$ molar & 28 & \\
\hline
\end{tabular}

Figura 1 - Protocolo Odontolegal: tabela para preenchimento de exame direto no arco dental superior, LAF/CEMEL, Ribeirão Preto, SP, Brasil.

\begin{tabular}{|c|c|c|c|}
\hline Dente & Tooth & $\begin{array}{c}\text { Notação Dental } \\
\text { FDI World Dental Federation } \\
\text { Notation }\end{array}$ & Comentário / Comment \\
\hline 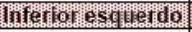 & menerime & (1) & 代 \\
\hline $3^{\circ}$ molar & $3^{r t}$ molar & 38 & \\
\hline $2^{\circ}$ molar & $2^{n s}$ moler & 37 & \\
\hline $1^{\circ}$ molar & $1^{1 t}$ moler & 36 & \\
\hline $2^{\circ}$ pré-molar & $2^{\text {nd }}$ premolar & 35 & \\
\hline $1^{\circ}$ pré-molar & $1^{\text {st }}$ premolar & 34 & \\
\hline Canino & Canine & 33 & \\
\hline Incisivo lateral & Lateral incisor & 32 & \\
\hline Incisivo central & Central incisor & 31 & \\
\hline Inferios disido & 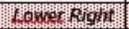 & (I) & (1) \\
\hline Incisivo central & Central incisor & 41 & \\
\hline Incisivo lateral & Lateral incisor & 42 & \\
\hline Canino & Canine & 43 & \\
\hline $1^{\circ}$ pré-molar & $1^{\text {st }}$ premolar & 44 & \\
\hline $2^{\circ}$ pré-molar & $2^{\text {ro }}$ premolar & 45 & \\
\hline $1^{\circ} \mathrm{molar}$ & $1^{2}$ molar & 46 & \\
\hline $2^{\circ}$ molar & $2^{10}$ molar & 47 & \\
\hline $3^{\circ} \mathrm{molar}$ & $3^{r d}$ molar & 48 & \\
\hline
\end{tabular}

Figura 2 - Protocolo Odontolegal: tabela para preenchimento de exame direto no arco dental inferior, LAF/CEMEL, Ribeirão Preto, SP, Brasil. 


\section{Informações sobre próteses e outras particularidades odontológicas}

Após o detalhamento dos dentes de ambos os arcos, são descritas informações acerca da presença ou ausência de peças protéticas, além da descrição de características peculiares encontradas em toda extensão da maxila e ou mandíbula. Esta etapa é realizada de forma separada para que achados peculiares encontrados nos arcos sejam descritos de forma completa e em conjunto.

\section{Perfil antropológico}

O perfil antropológico é traçado através de método qualitativo antroposcópico, levando em consideração as características ósseas presentes. Para a determinação do sexo através do crânio é analisado: forma da glabela/ crista supraorbital, presença da protuberância occipital, tamanho do processo mastóide, tamanho e forma do mento, presença da crista supramastóide, altura/robustez do zigomático e alargamento do ângulo mandibular. Para a estimativa da ancestralidade: forma do crânio, perfil facial, ossos nasais, abertura nasal, espinha nasal, formato do palato, sutura palatina e mento. Para a estimativa da idade é levado em consideração, além de outros elementos, as suturas cranianas e a cronologia de erupção e mineralização da dentição. Para a estimativa da estatura e destreza manual não são utilizados dados do crânio, sendo utilizados os ossos longos. Importante ressaltar que o perfil antropológico é obtido a partir do exame completo em Antropologia Forense.

\section{Informações radiográficas}

O passo seguinte consiste na obtenção de informações radiográficas, através da realização de radiografias periapicais em regiões com dentes presentes, bem como radiografia panorâmica e radiografia do seio frontal.

\section{Odontograma}

Após as tomadas radiográficas, é elaborado o odontograma, em forma gráfica, por meio de desenhos esquemáticos com legenda das particularidades encontradas nos arcos dentais superior e inferior, com base nas informações coletadas no exame direto post mortem (Figura 3), principalmente com enfoque em questões morfológicas (por exemplo, forma das restaurações dentais). Por esse motivo é adotado o odontograma na versão anatômica em detrimento do odontograma que traz apenas o esquema de faces.

\section{Registros fotográficos}

A etapa fotográfica consiste na realização de fotografias em diferentes vistas do crânio: frontal, lateral direita, lateral esquerda, superior, inferior e posterior, além de fotos aproximadas dos arcos dentais ou de achados odontológicos relevantes (Figuras 4 e 5). A escala é utilizada na fotografia do crânio articulado no início da etapa fotográfica.

\section{Aproximação facial forense}

A próxima etapa trata-se da reconstrução facial forense, ou aproximação facial forense, que é realizada pelo método digital, por meio da digitalização do crânio e obtenção de uma imagem em três 
dimensões para a confecção de uma aproximação facial, aliado ao exame antropológico. Essa etapa é realizada em parceria com a EBRAFOL - Equipe Brasileira de Antropologia Forense e
Odontologia Legal. Essa etapa não é realizada em todos os casos, visto que para sua realização é necessário que o crânio esteja completo e sem presença de fraturas no viscerocrânio.
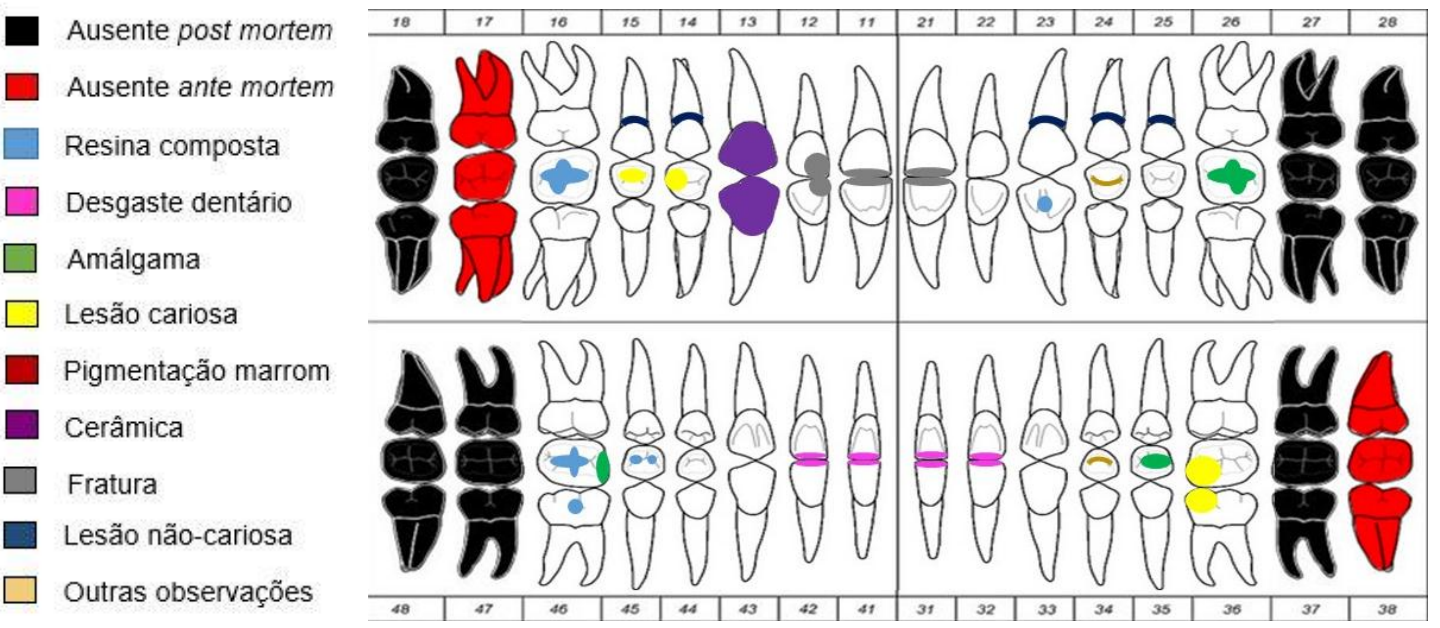

Figura 3 - Protocolo Odontolegal: odontograma com legenda (preenchimento ilustrativo), LAF/CEMEL, Ribeirão Preto, SP, Brasil.

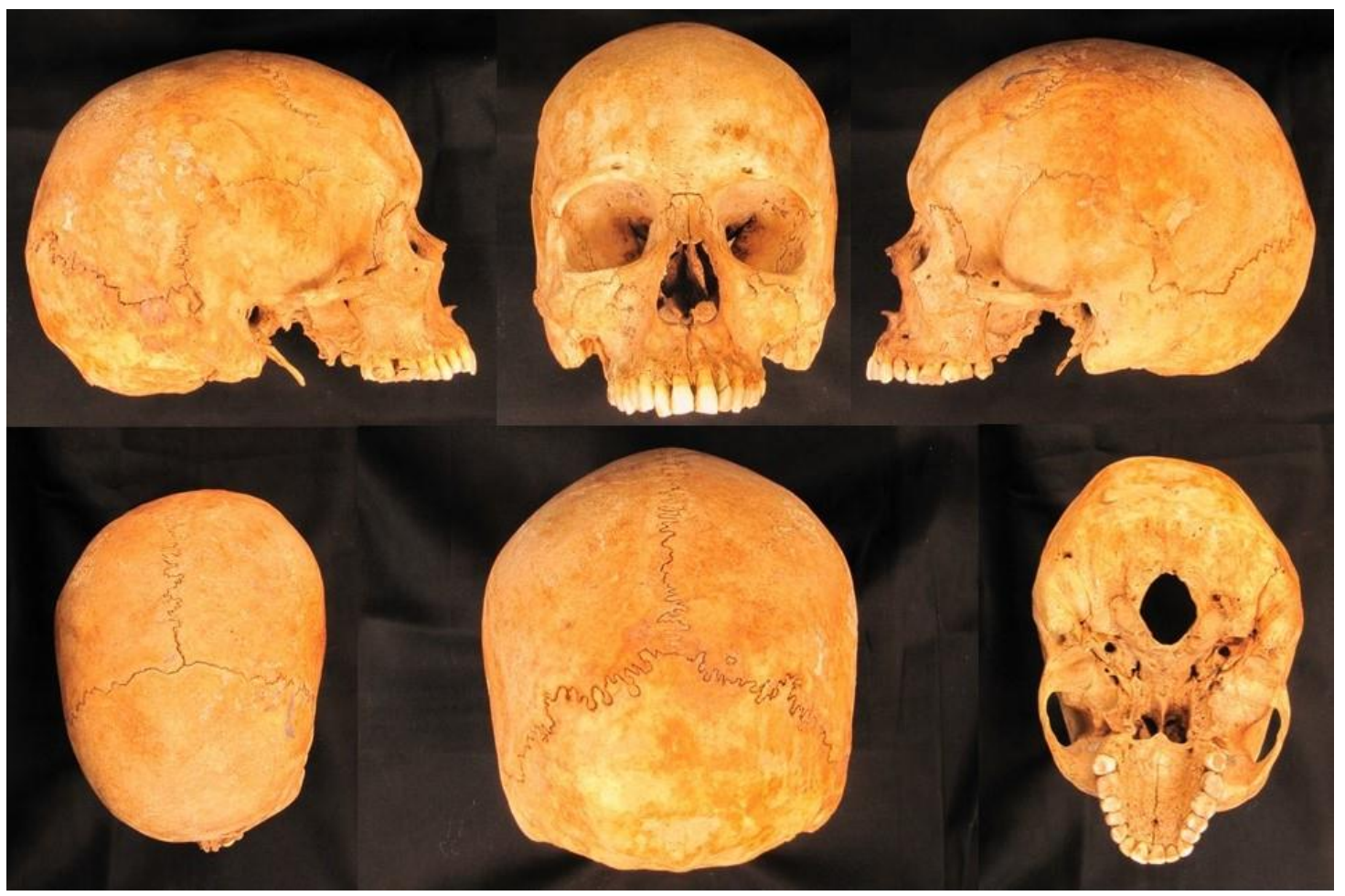

Figura 4 - Protocolo Odontolegal: sequência do protocolo fotográfico (crânio), LAF/CEMEL, Ribeirão Preto, SP, Brasil. 


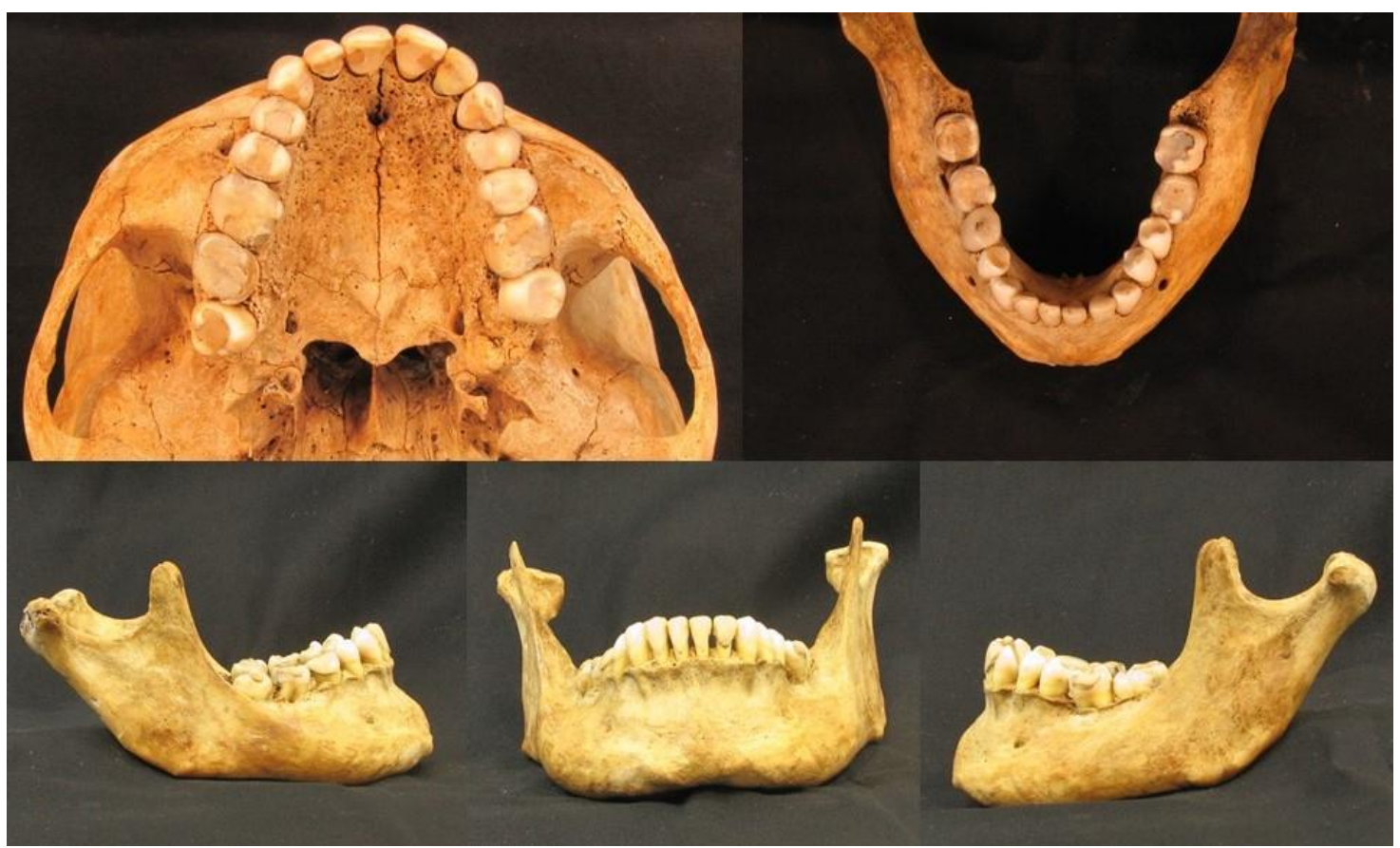

Figura 5 - Protocolo Odontolegal: sequência do protocolo fotográfico (arcos dentais), LAF/CEMEL, Ribeirão Preto, SP, Brasil.

\section{Exame dos dados ante mortem (AM)}

$\mathrm{Na}$ Figura 6 é possível verificar os itens que compõem o referido protocolo e as etapas finais do protocolo odontolegal (LAF/CEMEL), que se referem a itens dependentes da localização de uma provável vítima desaparecida. No exame dos dados ante mortem serão descritos detalhadamente cada informação ante mortem encaminhada. Em casos em que não seja possível a coleta de dados ante mortem, os espaços referentes a essas informações não são completados, sendo registrados somente quando alguma informação da pessoa desaparecida for encaminhada.

\section{Confronto Odontolegal}

Nesta etapa será confeccionada uma tabela, realizando a comparação entre os dados ante mortem e post mortem com imagens e explicação textual de cada achado.

\section{Conclusão}

$\mathrm{Na}$ conclusão constará o resultado do exame (identificação positiva, possível, provável ou exclusão, de acordo com os critérios estabelecidos pela ABFO American Board of Forensic Odontology) ${ }^{6}$.

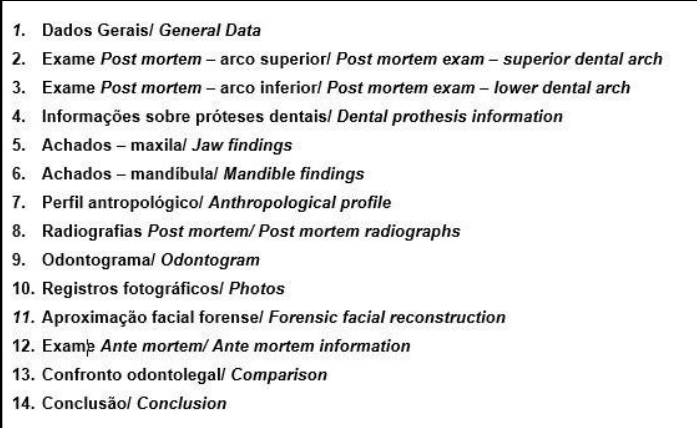

Figura 6- Compilação dos dados e sequência do protocolo odontolegal (LAF/CEMEL). 


\section{DISCUSSÃO}

A análise da literatura mostra que a maioria dos autores obedece uma determinada sequência nas perícias em Odontologia Legal. Entretanto é perceptível que alguns itens são de fundamental importância para sua amplitude e eficácia, uma vez que protocolos mais simplificados acabam por menosprezar itens primordiais durante a realização de uma perícia, podendo prejudicar ou inviabilizar os objetivos almejados ${ }^{7}$. E, nesse sentido, um protocolo de identificação odontolegal precisa ser minucioso e permitir uma interpretação mundial, bem como possuir aplicabilidade, baixo custo e eficácia, mesmo que em condições adversas ${ }^{8}$.

Cada indivíduo tem particularidades em seus arcos dentais que podem estabelecer sua identidade, pela enorme variedade de caracteres individualizadores proporcionados pelas peças dentais ${ }^{9}$. Nesse contexto, o exame de um corpo por meio dos achados odontológicos pode ter papel primordial em uma perícia criminal, por não existirem dentições iguais, e dada a resistência da estrutura dental, podem fornecer informações particulares e contribuir em investigações criminais ${ }^{10-12}$.

Assim como recomendado no protocolo objeto deste trabalho, outros estudos demonstram que todas as informações levantadas no exame dental devem ser registradas em odontograma próprio, preferivelmente em um modelo internacional, para facilitar a troca de dados entre diferentes países ${ }^{10}$. É importante salientar quais faces dos dentes foram envolvidas nos procedimentos observados durante o exame clínico, bem como o tipo do material utilizado, o tamanho, abrangência e proporcionalidade em relação à figura do odontograma ${ }^{13}$.

O modelo de odontograma mais indicado é o modelo proposto pela INTERPOL, pois contempla as cinco faces coronárias e permite a visualização integral das restaurações ${ }^{14}$. Ainda que 0 modelo utilizado neste protocolo não seja o mesmo modelo da INTERPOL, trata-se de um esquema que abrange as cinco faces, sendo uma opção viável por se aproximar da ideia da estrutura dental, tendo em vista que 0 documento será acessado por autoridades judiciais e policiais, normalmente leigas em Odontologia e, desta forma, quanto mais próxima a imagem, melhor o entendimento.

Em situações de desastres em massa, a INTERPOL recomenda os seus formulários ${ }^{15}$, como forma de uniformidade e padronização dos registros coletados nestas situações $^{16}$. Outra recomendação do protocolo preconizado pela INTERPOL é a utilização do sistema de informações intitulado DVI System International, da empresa PLASSDATA (atual versão 5) ${ }^{17}$ para a inserção dos dados e facilitar o confronto dos dados ante mortem e post mortem e servir como armazenamento digital das informações ${ }^{16}$. Os formulários preconizados pela INTERPOL são divididos em duas seções principais, formulário amarelo (dados ante mortem) e formulário rosa (dados post mortem) ${ }^{15}$. No interior de cada formulário possui a seção "Odontologia", onde serão listadas todas as informações odontológicas coletadas ${ }^{8}$.

Dentre as informações que devem ser anotadas e registradas no odontograma, 
estão as patologias existentes, restaurações, ausência de dentes, próteses, tratamentos endodônticos, tipos de oclusão e outros dados a critério do cirurgiãodentista, sendo adotado para a identificação dos dentes sistema decimal da FDI, ilustrado na Figura 1 e Figura $2^{18}$. A notação dental utilizada no Brasil e na maioria dos países é a preconizada pela FDI (Federação Dentária Internacional) e aprovada pela Organização Mundial de Saúde (OMS), em 1970, conhecida por Notação ISO $3950^{19}$.

Estudo nos mostra a importância das equipes que atuam em Odontologia Legal estarem aptas a identificar o sistema de notação utilizado em um prontuário, possibilitando a interpretação de uma documentação ante mortem e uma possível identificação humana, bem como, que os cirurgiões-dentistas mantenham um padrão de notação dental utilizado em seus consultórios e informem qual deles fora utilizado quando alguma documentação for solicitada para comparações com finalidade de identificação ${ }^{20}$.

De acordo com Pereira (2003) ${ }^{21}$, as fotografias importantes para identificação deverão possuir, quando possível: face completa, dentes anteriores em oclusão, vistas bucais dos dentes em oclusão do lado direito e do lado esquerdo, vistas oclusais mandibulares e maxilares, "close" de qualquer característica em especial, como coroas protéticas, próteses fixas, aparelhos removíveis, aparelhos ortodônticos, toro mandibular, diastema, máoclusões e dentes supranumerários ${ }^{21}$. Nesse sentido, as etapas de esquematização gráfica em odontograma e registros fotográficos realizados durante a sequência deste protocolo são realizados no intuito de descrever minuciosamente 0 objeto da perícia, minimizando as chances de desperdiçar informações cruciais para a investigação.

Coutinho et al. $(2014)^{10}$ salientam que durante a perícia, 0 Perito Odontolegista deve utilizar as vias de acesso da cabeça e pescoço e fazer anotações, desenhos, esquemas, fotografias e tudo que for necessário para que $o$ exame fique bem descrito $e$ detalhado, pois o ideal é que não sejam necessários esclarecimentos posteriores, por meio de um segundo exame com o corpo já em decomposição ou esqueletizado, na medida em que não trarão as mesmas informações ${ }^{10}$.

O exame antropológico é realizado com a finalidade de determinar um perfil biológico e auxiliar a identificação de uma ossada desconhecida ${ }^{5}$. Os dados obtidos por meio de técnicas de Antropologia Forense geram parâmetros para exclusão de suspeitos (estatura, sexo, idade, ancestralidade, dentre outros) $)^{22}$. Em alguns casos, o perfil bioantropológico servirá como triagem com vistas a uma futura análise de DNA e, com isso, reduz-se o número de análises de DNA, e consequentemente, há redução de custos e do tempo do processo ${ }^{5}$.

A reconstrução, ou aproximação, facial é um método que propicia a ocorrência do reconhecimento, direcionando a investigação para a real identidade associada a determinados restos mortais sem identificá-10 ${ }^{23,24}$. O reconhecimento pode ser passo precedente essencial ao processo de identificação visando, prioritariamente, a diminuição do número de 
sujeitos suspeitos $^{25}$. A reconstituição da face, quando associada a outras informações, como exame antropológico, de sinais individuais, dos arcos dentais, de radiografias, além de exames de DNA, pode contribuir favoravelmente para $\circ$ processo de identificação humana ${ }^{25}$.

A técnica de aproximação facial utilizada no presente protocolo trata-se da técnica digital, uma vez que os materiais recebidos para a realização do exame pericial encontram-se muitas vezes degradados ou fragilizados, sendo inviável a realização de moldagem ou modelagem diretamente no crânio, como usualmente recomendado na técnica manual.

A reconstrução facial forense digital tornou-se viável com o surgimento da tecnologia da informação e 0 desenvolvimento da imaginologia médica e novos softwares de imagem $3 D$ e de reconstrução ${ }^{26}$. Para a realização desse tipo de aproximação facial faz-se necessário dados relativos à espessura dos tecidos moles da face e do estudo antropológico do crânio a ser reconstruído ${ }^{26,27}$. Esta etapa do protocolo somente foi incorporada a partir da parceria feita com a EBRAFOL no ano de 2014.

A importância da realização dos exames odontolegais, principalmente aqueles relacionados com a identificação humana, mostra a relevância da implantação dos serviços de Odontologia Legal nos Institutos Médico Legais de todo o país $^{4,28}$. Nesse contexto, salienta-se a conscientização dos cirurgiões-dentistas sobre $\mathrm{o}$ correto preenchimento $\mathrm{e}$ arquivamento das peças que compõem a documentação odontológica, não só pela sua importância clínica, mas por poderem fornecer esclarecimentos relevantes à Justiça $^{1,29,30}$.

Neste contexto, o Código de Ética Odontológica $^{31}$ dispõe que é obrigatória a elaboração e a manutenção de forma legível e atualizada de prontuário e a sua conservação em arquivo próprio seja de forma física ou digital. E o Conselho Federal de Odontologia disponibiliza, em formato digital, um "modelo" e sequência de prontuário odontológico que atende, minimamente, as exigências éticas e legais da prática odontológica ${ }^{14}$. E esse "modelo" de prontuário proposto pelo CFO, além de sua importância clínica, torna viável a utilização do protocolo descrito neste estudo em casos de confronto odontolegal.

A Odontologia Legal é notadamente útil em casos de corpos esqueletizados, cadáveres em fase adiantada de decomposição, desmembrados ou carbonizados $^{12,18}$. Porém, sua utilização é inviabilizada sem 0 prévio registro odontológico, uma vez que utiliza dados e registros dentais ante mortem para fazer comparações com os dados coletados post mortem. Essas comparações são feitas através de informações e registros contidos no prontuário odontológico. Deste modo, comparando-se o prontuário odontológico com a situação dental encontrada no cadáver, é possível que se chegue à correta identificação ${ }^{7}$, como verificado em diversos estudos $^{1,9,11-13,18,29,32-37}$.

$E$, embora existam documentações odontológicas satisfatórias, muitas vezes os cirurgiões-dentistas registram somente os procedimentos a realizar, omitindo a condição na qual os dentes se encontram 
antes e após a finalização do tratamento, dificultando ou, até mesmo, impossibilitando uma identificação odontolegal ${ }^{18}$. Desse modo a identificação será realizada por outro método, DNA, por exemplo, o que protela a entrega e aumenta os custos, uma vez que em casos em que a identificação não acontece com sucesso, o IML não pode fornecer a Declaração de óbito, impossibilitando a liberação do corpo aos familiares e, até mesmo, deixando o inumado como desconhecido ${ }^{13}$.

Entre a coletânea de documentos elaborados pelo cirurgião-dentista que compõem um prontuário odontológico estão: modelos de estudo, fotografias, odontogramas, radiografias e outros documentos, os quais reúnem informações que podem ser decisivas na eventual necessidade de identificação do indivíduo, pois registram características únicas, imutáveis e perenes do indivíduo ${ }^{38}$. Isso mostra a importância da padronização dos registros post mortem, no intuito de aumentar meios que subsidiem o confronto odontolegal, assim como realizado neste protocolo.

Dentre os vários documentos que compõem o prontuário odontológico, destacam-se, para fins forenses, os exames por imagem, que podem ser utilizados para auxiliar na identificação humana, incluindo a determinação do sexo, ancestralidade e, principalmente, a estimativa da idade ${ }^{11,39}$. A variedade de incidências radiográficas, usuais e fundamentais na terapêutica odontológica, registram imagens de particularidades dentais, como detalhes anatômicos, presença de materiais restauradores e tratamentos reabilitadores, entre muitos outros, e, por esse motivo, são valiosas ferramentas nos casos de identificação humana ${ }^{40,41}$, sendo sua efetividade e utilização comprovadas ${ }^{11,18,36}$. $\mathrm{E}$, por esse motivo, o protocolo proposto utiliza uma diversidade de incidências e tipos radiográficos, aqui incluídas as radiografias periapicais, panorâmica e de seio frontal, visto a importância desses exames em processos de identificação $^{11,18,36,40,41}$.

Como descrito anteriormente, a identificação odontolegal feita através do protocolo LAF/CEMEL é realizada de forma manual, através da confecção de uma tabela onde são comparados cada achado registrado no exame post mortem e ante mortem do corpo não identificado com os respectivos suspeitos. Por esse motivo, 0 seu uso é limitado em situações de desastres em massa, sendo mais indicado, nesses casos, a utilização de softwares ${ }^{17,42-}$ 47 computacionais que realizam uma busca dentro de bancos de dados apresentando uma lista dos suspeitos mais prováveis ${ }^{44}$. E é importante salientar que após o software disponibilizar um ranking das principais correspondências, deve-se realizar uma comparação mais aprofundada dos registros dentais e radiografias, a fim de se chegar a uma identificação ${ }^{44}$, sendo realizada, desse modo, de forma manual, assim como no protocolo descrito.

\section{CONCLUSÃO}

A utilização do protocolo odontolegal apresentado permite a coleta de uma série de informações odontológicas que podem ser utilizadas para fins de identificação humana, padronizando a 
coleta das informações e minimizando as chances de desperdiçar informações cruciais para a resolução de uma investigação podendo ser utilizado como modelo nos serviços de odontologia legal existentes no Brasil.

\section{ABSTRACT}

The protocol from the Laboratory of Forensic Anthropology (LAF) in the Center of Legal Medicine at the University of São Paulo (USP) was structured to obtain an anthropological profile of each skeleton admitted for evaluation, in order to assess the characteristics of sex, ancestry, age, height, and manual dexterity. With the insertion of dental examination in the laboratory routine, a Forensic Odontology protocol was organized by USP - School of Dentistry of Ribeirão Preto team, with the purpose of systematizing and organizing the dental data collection during the post mortem exam, to support processes for human identification through the dental information. The aim of this paper is to present the protocol's description. It was concluded that the protocol allows the collection of many dental data that can be used for human identification.

\section{KEYWORDS}

Forensic dentistry; Human identification; Forensic anthropology.

\section{REFERÊNCIAS}

1. Silva RF, Daruge Junior E, Pereira SDR, Almeida SM, Oliveira RN. Identificação de cadáver carbonizado utilizando documentação odontológica. Rev Odonto Ciência. 2008;23(1):90-3.

2. Peres AS, Peres SHCS, Nishida CL, Grandizoli DK, Ribeiro IWJ, Gobbo LG, et al. Peritos e perícias em Odontologia. Rev Odontol da Univ Cid São Paulo. 2007;19(3):320-4.

3. Brasil. Conselho Federal de Odontologia. Resolução CFO-63/2005. Consolidação das normas para procedimentos nos Conselhos de Odontologia. 2005.

4. Ribas-e-Silva V, Terada ASSD, Silva RHA. A importância do conhecimento especializado do cirurgião-dentista nas equipes de perícia oficial do Brasil. Rev Bras Odontol Leg RBOL. 2015;2(1):68-90. http://dx.doi.org/10.21117/rbol.v2i1.22.

5. Francisco RA, Silva RHA, Pereira JM, Soares EG, Júnior EM, Iwamura ESM, et al. A antropologia forense como triagem para as análises da genética forense. Saúde, Ética \& Justiça. 2013;18(1):128-33.

6. Odontology, American Board od Forensic. Section I: Preface, Acknowledgments, Backgrpund F\& P. Diplomates Reference Manual. 2016;(March):1-173.

7. Frari $P$, Iwashita AR, Carlos JCFG, Scanavini MA, Daruge Junior E. A importância do odontolegista no processo de identificação humana de vítima de desastre em massa. Sugestão de protocolo de exame técnico-pericial. Odonto. 2008;31:38-44.

http://dx.doi.org/10.15603/21761000/odonto.v16n31p38-44.

8. Biancalana RC, Vieira MGDM, Figueiredo BMJ, Vicente SAF, Dezem TU, Silva RHA. Desastres em massa: a utilização do protocolo de dvi da interpol pela odontologia legal. Rev Bras Odontol Leg RBOL. 2015;2(2):48-62. http://dx.doi.org/10.21117/rbol.v2i2.38.

9. Carvalho CM, Nazar RJ, Moreira AMC, Bouchardet $\mathrm{FCH}$. Identificação humana pelo exame da arcada dentária. Arq bras odontol. 2008;4(21):67-9.

10. Coutinho CGV, Ferreira CA, Queiroz LR, Gomes LO, Silva UA. O papel do Odontolegista nas perícias criminais. Rev da Fac Odontol - UPF. 2014;18(2):217-23. http://dx.doi.org/10.5335/rfo.v18i2.3399.

11. Scoralick RA, Barbieri AA, Moraes ZM, Francesquini Júnior L, Daruge Júnior $E$, Naressi SCM. Identificação humana por meio do estudo de imagens radiográficas odontológicas: relato de caso. Rev Odontol UNESP. 2013;42(1):67-71. http://dx.doi.org/10.1590/S180725772013000100012

12. Silva RF, Dias PEM, Picoli FF, Rodrigues LG, Mundim MBV, Franco A. Inconsistências antropológicas observadas em corpo putrefeito identificado por registros odontológicos - relato de caso pericial. Rev Bras Odontol Leg RBOL. 2015;2(1):125-36. 
http://dx.doi.org/10.21117/rbol.v2i1.25.

13. Paranhos LR, Caldas JCF, Iwashita AR, Scanavini MA, Paschini RC. A importância do prontuário odontológico nas perícias de identificação humana. RFO. 2009;14(1):14-7.

14. Brasil. Conselho Federal de Odontologia. Prontuário odontológico: uma orientação para o cumprimento da exigência contida no inciso VIII Art. 5 do Código de Ética Odontológica. 2004.

15. Interpol. DVI FORMS. Acessado em: 30/02/2017; Disponível em: http://www.interpol.int/INTERPOLexpertise/Forensics/DVI.

16. Mânica S. Outros desafios além da identificação de vítimas para o dentista forense que atua em desastres em massa considerações em literatura. Rev Bras Odontol Leg RBOL. 2016;3(1):60-9. http://dx.doi.org/10.21117/rbol.v3i1.53.

17. Plassdata. DVI System International. Acessado em: 30/02/2017; Disponível em: http://www.plassdata.com.

18. Cevallos LB, Galvão MF, Scoralick RA. Identificação humana por documentação odontológica: Carbonização subsequente á impacto de Helicóptero no solo. Rev Conex SIPAER. 2009;1(1):191-202.

19. ISO. ISO 3950:2016. Designation system for teeth and areas of the oral cavity. 2016.

20. Beaini TL, Dias PEM, Melani RFH. Importância pericial dos sistemas de notação dental - revisão de literatura. Rev Bras Odontol Leg RBOL. 2016;3(1):519. http://dx.doi.org/10.21117/rbol.v3i1.13.

21. Pereira RM. A contribuição da odontologia legal na identificação humana em acidentes aeronáuticos. Dissertação (Mestrado). Faculdade de Odontologia de São Paulo da Universidade de São Paulo. São Paulo, SP; 2003. 187p.

22. Terada ASSD, Leite NLP, Silveira TCP, Secchieri JM, Guimarães MA, Silva RHA. Human identification in forensic dentistry from a photographic record of smile: a case report. Rev Odontol UNESP. 2011;40(404):199-202.

http://dx.doi.org/10.1097/PAF.0000000000 $\underline{000148 .}$.

23. Nelson LA, Michael SD. The application of volume deformation to three-dimensional facial reconstruction: A comparison with previous techniques. Forensic Sci Int.
1998;94(3):167-81.

http://dx.doi.org/10.1016/S03790738(98)00066-8.

24. Theodoro MJA. Aplicação da computação gráfica na reconstrução de face para reconhecimento: um estudo de caso. Dissertação (Mestrado). Faculdade de Medicina de Ribeirão Preto da Universidade de São Paulo. São Carlos, SP; 2011. 87p.

25. Santos WDF, Diniz PRB, Santos AC, Martin CCS, Guimarães MA. Definições de pontos craniométricos em imagens multiplanares de ressonância magnética (RM) para fins de reconstrução facial forense. Medicina (Ribeirão Preto). 2008;41(1):17-23.

26. Fernandes CMS. Análise das reconstruções faciais forenses digitais caracterizadas utilizando padrões de medidas lineares de tecidos moles da face de brasileiros e estrangeiros. Tese (Doutorado). Faculdade de Odontologia de São Paulo da Universidade de São Paulo. São Paulo, SP; 2010; 152p.

27. Rocha SS, Ramos DLP, Cavalcanti MGP. Applicability of 3D-CT facial reconstruction for forensic individual identification. Pesqui Odontol Bras. 2003;17(1):24-8. http://dx.doi.org/10.1590/S151774912003000100005.

28. Bandeira RO, Menezes LMB, Oliveira PMC, Correia AM. Forensic dental examinations carried out in a large city in northeastern Brazil. RGO. 2013;61(3):34955.

29. Carvalho GP, Matoso RI. O odonto-legista e um corpo não-identificado. RGO. 2010;58(3):405-9.

30. Silva RF, Oliveira CFP, Souza POC, Rodrigues LG, Mundim MBV, Franco A, et al. Repercussões periciais diante de falha no preenchimento de prontuário odontológico - relato de caso pericial. Brazilian J Forensic Sci , Med Law Bioethics, Med Law Bioeth. 2015;4(2):209_ 1.

http://dx.doi.org/10.17063/bjfs4(2)y201520 g.

31. Brasil. Resolução CFO no 118, de 11 de maio de 2012. Revoga o Código de Ética Odontológica aprovado pela Resolução CFO-42/2003 e aprova outro em substituição. Brasília. 2012. 
32. Tsuchiya MJ, Gomes EM, Abe DM, Oliveira FVN, Massaoka C, Oliveira RN. Human identification through the analysis of dental records registered in the context of a Dental Institution. RGO. 2013; 6(3):389-93.

33. Ferreira R, Prado MM, Barbieri AA, Daruge Júnior E. Utilização de registros odontológicos para identificação humana. RSBP. 2009;6:95-9. http://dx.doi.org/10.1590/S2176$\underline{94512011000200007 .}$.

34. Ferreira RF, Chaves $P$, Paranhos LR, Lenza MA, Daruge Júnior E. Utilização de documentação ortodôntica na identificação humana*. Dent Press. 2011;16(2):52-7. http://dx.doi.org/10.1590/S2176$\underline{94512011000200007 .}$.

35. Almeida SM, Delwing F, Azevedo JAP, Nogueira RKJ, Falcão FP, Carvalho SPM, Effectiveness of dental records in human identification. 2015;502-6. http://dx.doi.org/10.1590/1981863720150003000213017.

36. Musse JO, Marques JAM, Vilas-Boas CDF, Sousa RSV, Oliveira RN de. Importância pericial das radiografias panorâmicas e da análise odontológica para identificação humana: relato de caso. Rev Odontol da UNESP. 2011;40(2):108-11.

37. Terada ASSD, Araujo LG, Paranhos LR, Silveira TCP, Guimarães MA, Silva RHA. Orthodontic Use of Documentation in Identification of a Skeletonized Body in Legal Dental Practice. Int J Odontostomatol. 2014;8(1):41-6. http://dx.doi.org/10.4067/S0718381X2014000100004.

38. Silva RF, Pereira SDR, Daruge E, Daruge Júnior EFJ. A confiabilidade do exame odontolegal na identificação humana. RObrac. 2004;13(35).

39. Carvalho SPM, Silva RHA, Lopes-Júnior C, Sales Peres A. A utilização de imagens na identificação humana em odontologia legal. Rodiol Bras . 2009;42(2):125-30. http://dx.doi.org/10.1590/S0100$\underline{39842009000200012 .}$.

40. Silva RF, Pereira SDR, Mendes SDSC, Marinho DEA, Daruge Junior E. Radiografias odontológicas: fonte de informação para identificação humana. Odontol Clin-Científ. 2006;5:239-42.

41. Gruber J, Kameyama MM. O papel da Radiologia em Odontologia Legal The role of radiology in forensic dentistry. $2001 ; 35(1951): 263-8$.

42. Torpet LA. Dvi system international: software assisting in the thai tsunami victim identification process. 2005;23(1):19-25.

43. Clement JG, Winship V, Ceddia J, Al-amad S. New software for computer-assisted dental-data matching in Disaster Victim Identification and long-term missing persons investigations: "DAVID Web." 2006;24-9.

http://dx.doi.org/10.1016/j.forsciint.2006.02. $\underline{006}$.

44. Adams BJ, Aschheim KW. Computerized Dental Comparison: A Critical Review of Dental Coding and Ranking Algorithms Used in Victim Identification. 2016;61(1):76-86. http://dx.doi.org/10.1111/1556-4029.12909.

45. Al-Amad SH, Clement JG, McCullough MJ, Morales A, Hill AJ. Evaluation of two dental identification computer systems: DAVID and WindID3. J Forensic Odontostomatol. 2007;25(1):23-9.

46. Chomdej T, Pankaow W, Choychumroon S. Intelligent dental identification system (IDIS) in forensic medicine. Forensic Sci Int. 2006;158:27-38. http://dx.doi.org/10.1016/j.forsciint.2005.05. $\underline{001}$.

47. Kogon SL, Petersen KB, Locke JW, Petersen NO, Ball RG, Petersen KB, et al. A Computerized Aid to Dental Identification in Mass Disasters. Can Soc Forens Sci J. 2016;5030. http://dx.doi.org/10.1080/00085030.1975.1 $\underline{0757220 .}$. 